\section{The limitations of critical incident stress debriefing}

Sir - I wish to commend Dr Louise Conlon and Prof Thomas Fahy in relation to their editorial Debriefing for Acute Trauma - a Welcomed Demise?"

As the major psychiatric advisor to the Military, Irish Marine Emergency Service and the Gardaí in relation to when and where critical incident stress debriefing (CISD) should occur, I would like to make the following observations.

CISD is only of use when a major incident has occurred, usually when there is a significant loss of life. It is very important that the critical incident stress debriefing only occurs after the operational debrief. The debriefers need to be highly trained particularly in relation to group dynamics. My major fear is the risk of scape goating. I am well aware of the negative findings of the Cochrane Review by Wesley Bedell ${ }^{2}$ and more recent findings by Shalev in relation to the poor outcome from CISD. I would consider that CISD is an inappropriate intervention in relation to road traffic accidents even when there is major trauma. It is best kept for major incidents in which a number of personnel were involved and carried out by their own peers who are respected.

There is plenty of evidence that CISD does not prevent post traumatic stress disorder, so why, on occasions do I recommend it? For the one reason as was described by one of my English colleagues, "the punters like it". The other reason, one which I consider to be very significant, is that it ameliorates the anger felt by the victims of the trauma. By sending in a critical incident stress debriefing team to a unit, the message is being given that the authorities care about the unit's emotional as well as physical well being.

My work brings me into contact with a large number of litigants taking action against various state bodies for post traumatic stress disorder. During the interviews and assessments, it is frequent that I hear the litigants explain, that the only reason that they are seeking legal redress is to seek some sort of recognition by the authorities that they have received an emotional insult. Many say that they would not have proceeded with High Court action, except for the fact that they felt ignored after the traumatic event. There may be some truth in this.

In relation to the military traumatic events, which occurs when units are serving overseas in peacekeeping roles, reality makes critical incident stress debriefing an aspiration rather than a fact. Life threatening events occur at such a rate that if we were to act after every event as recommended by those involved in the 'disaster industry', military operations would rapidly come to a halt and the units would cease to function. The pendulum has swung to a ridiculous extreme at present, and I hope now we can work our way back to a mature assessment of when CISD is initiated and when it is best avoided. It comes as no surprise to me that such intervention, when badly handled, with inexperienced, but often well meaning personnel, its effects are counter productive.

In short, I recommend, that it is utilised sparingly, with highly trained personnel who are peer supporters of the at risk population, and only after major events. It dissipates anger which is often directed at those in authority and promotes unit cohesion when done in a proper manner. It should never get in the way of operational debriefing or police investigations. The legal system may be going overboard in expecting it after relatively minor events. As things stand, we can be legally liable for initiating CISD and also for not initiating it.

In other words, we are dammed if we do and we are dammed if don't. In these circumstances, we are best practising our skills wisely and in educating the legal profession and those we serve on the benefits and the marked limitations of critical incident stress debriefing.

John Tobin, MPRCPsych, FRCPC, BSc,

Consultant Psychiatrist to the Irish Defence Forces and visiting psychiatrist to the Garda Siochana.

References

1. Psychological debriefing for acute trauma a welcomed demise, Conlon L, Fahy T. Irish Journal of Psychological Medicine 2001; 18(2): 43-4.

2 . Wesley S, Rose S, Bisson J. An Aspirate Review of brief psychological interventions ('Debriefing') for the Treatment of Immediate Trauma Related Symptoms and Prevention of Post Traumatic Stress Disorder, London. The Cochrane Library 1998; 2: 1-17.

\section{Diagnostic criteria used to assess ADHD/hyperkinetic disorder}

Sir - The diagnosis of ADD/ADHD, or hyperkinetic disorder remains extremely controversial among health professionals, parents, the media, and the public at large. The diagnostic criteria used to assess this disorder remain crucial as the two dominant diagnostic criteria yield substantially different prevalence rates, which may influence access to treatment. The World Health Organisation's ICD-10 schema, ' which remains dominant in Europe, includes the diagnosis of hyperkinetic disorder. A recent examination of prevalence rates in Great Britain revealed a rate among 5-15 year olds of $1.4 \% .^{2}$ However it is widely accepted that using the American Psychological Association's DSM IV criteria, ${ }^{3}$ rates of ADD/ADHD are between 5\%-10\%. Although contested by Kewley, ${ }^{5}$ recent research ${ }^{6}$ indicates that the ICD-10 criteria identify a subset of children who are both younger and more seriously impaired than those diagnosed under DSM criteria.

As part of an examination of the prevalence of ADHD/ hyperkinetic disorder in the Republic of Ireland it was decided in early 2000 to contact all consultant psychiatrists to determine which diagnostic criteria they used. Using a list of all non-retired consultant psychiatrists in-post obtained from the Department of Health and Children, a short questionnaire, covering letter and SAE was posted to each consultant psychiatrist. Three postal reminders (and a duplicate questionnaire) were also sent. The survey response rate was $70 \%(n=26)$.

The first question asked what criteria respondents used to diagnose this disorder. Forty-two percent (11) of respondents mentioned using both the ICD and the DSM classification schemas. A further $27 \%$ (seven) of respondents mentioned the ICD classification scheme, but did not mention the DSM schema. Twenty-three percent (six) of respondents mentioned DSM criteria, without mentioning the ICD schema. Eight percent (two) of respondents mentioned neither the DSM or ICD schedules. A substantial number of respondents also mentioned using clinical histories/interviews, as well as diagnostic schemas.

The results indicate that substantial differences of opinion exist among consultant psychiatrists concerning the diagnostic schema used to assess ADHD/hyperkinetic disorder.

It is probable that such diagnostic differences influence access to both behavioural interventions and pharmaceutical treatments. Such differences would appear to raise important 
questions about equal access to diagnosis and treatment across the patient population.

Frank Houghton, Health Geographer,

Kevin Kelleher, Director of Public Health,

Department of Public Health, Mid-Western Health Board, Park View House, Pery Street, Limerick, Ireland.

\section{References \\ 1. World Health Organisation. The ICD-10 classificarion of mental and behavioural disorders diagnostic criteria. Geneva: WHO, 1993. \\ 2. Meltzer H, Gatward R, Goodman R, Ford T. Mental health of children and adolescents in Great Britain. London: The Stationery Office, 2000. \\ 3. American Psychiatric Association. Diagnostic and Statistical Manual of Mental Disorders. 4th ed. Washington, DC: Am Psychiatric Association, 1994. \\ 4. Morgan AM. Attention-Deficit/Hyperactivity Disorder. Preface. Pediatr Clin North Am $1999 ; 46(5)$ : xi-xii. \\ 5. Kewley GD. Personal paper: Attention deficit hyperactivity disorder is underdiagnosed and undertreated in Britain. BMJ 1998; 316; 1594-6. \\ 6. Tripp G, Luk SL, Schaughency EA, Singh R. DSM-IV and ICD-10: A comparison of the correlates of ADHD and Hyperkinetic Disorder. J Am Acad Child Adolesc Psychiatry 1999; $8(2): 157-164$ \\ Promoting potential in all our children}

Sir - The paper by James and Lawlor ${ }^{1}$ on the psychological problems of early school leavers was helpful in highlighting the significant problems experienced by young people who drop out of the school system early. They assert that effective interventions at primary school stage may have improved educational outcomes and that the relatively high level of attention problems could possibly have been detected earlier and treated, with the prevention of dropping out.

While it is possible that a small number of such young people with, for example, ADHD if treated with psycho-stimulants might survive in the school system, it is unlikely that this on its own would have a significant impact. In North America, despite significantly higher usage of psycho-stimulants and probably the best identification of children with attentional problems anywhere in the western world, rates of early dropout from school are still significantly high.

Much is known about the development of antisocial behaviour across childhood into young adulthood, but while we have an excellent grasp of the risk factors cumulatively leading to disruptive behaviour disorders, there is an incomplete picture of the role of protective factors in the process. Some of the risk factors such as poverty will not be influenced by clinical intervention. Social and para-educational interventions may have a greater impact on more children.

A recent longitudinal study ${ }^{2}$ extending over 20 years showed that participation in extra curricular activities between the ages of 10 and 14 seemed to protect individuals at high risk for behavioural problems/conduct disorder. Children who participated in such activities were less likely to drop out of school or be arrested. Childrens' competence and participation in these activities were independent of each other. Any intervention which focuses on the potential of children, independent of whatever risks and deficits they have, should be promoted by those responsible for providing an educational service for our young people and may be more important than the psychological support and treatment advocated by James and Lawlor.

Noel McCune, Consultant Child and Adolescent Psychiatrist, Child and Family Clinic, 2 Old Lurgan Road, Portadown, BT $635 \mathrm{SQ}$, Northern Ireland.

Reference

1. James D, Lawlor M. .Psychological problems in early school leavers. It J Psych Med 2001, $18 ; 7,2 ; 61-5$

School extracurricular activity participation as a moderator in the development of antisocial Patterns Child Dev 2000; 71: 502-16

\section{Recovered memories of sexual abuse}

Sir - In his article Fact or fantasy: A review of recovered memories of childhood sexual abuse, Michael DelMonte asks in relation to the alleged recollections of childhood sexual abuse by Freud's patients in the mid-1890s: "Were they fact or fiction?". There is strong evidence that the answer to this question is 'fiction', though in a rather different sense than that which Dr DelMonte has in mind. Several scholars who have examined the contemporary documents relating to Freud's 1896 seduction theory claims have noted, in the words of JG Schimek, that "Freud's later accounts of the seduction theory (particularly in 1914 and 1933) are widely discrepant from the way he initially presented it", and have concluded that "the knowledge of this original [childhood] trauma, whether considered as unconscious memory or fantasy, was based on Freud's interpretation and reconstruction; it was not directly revealed by the patient". ${ }^{2-8}$

Although in later accounts Freud stated that he had been led to postulate his seduction theory as a result of hearing patients' reports of early childhood sexual abuse, in fact he arrived at the theory that the precondition for hysteria and obsessional neurosis was an unconscious memory of sexual abuse in infancy prior to reporting a single instance of his having uncovered such abuse. ${ }^{9}$ Only four months later he sent off two papers in which he claimed to have analytically uncovered repressed memories of infantile sexual abuse for every one of 16 patients ( 13 diagnosed as 'hysterical' and three as 'pure' obsessionals). ${ }^{10}$

Although some patients may have been induced to 'repro. duce' fragmentary images under the influence of the quasi-hypnotic 'pressure technique' he was using at that time, ${ }^{11}$ Freud's introductory remarks in The aetiology of hysteria indicate that his analytic methodology was based essentially on the symbolic interpretation of patients' symptoms. ${ }^{12}$ And far from their reporting 'memories' of having been sexually abused in early childhood, as the traditional story has it, the patients insisted that they had "no feeling of remembering the scenes" Freud claimed to have uncovered, and assured him "emphatically of their unbelief"..$^{13}$

Evidentally Freud's clinical experiences in 1895-97 (the actual material concerning which he never published) ${ }^{14}$ were rather different from his later accounts which are the source of the traditional story of the seduction theory episode.

Allen Esterson,

1 A Cromwell Grove, Hammersmith, London W6 $7 R Q$, England.

References

1. Delmonte MM. Fact or fantasy: A review of recovered memories of childhood sexual abuse. Ir J Psych Med 2001; 18(3) 99-105.

2. Schimek JG. Fact and fantasy in the seduction theory: A historical review. J Am Psychoanalytic Association 1987; 35(4): 937-65

3. Cioffi F. Was Freud a liar? The Listener 1974; 7 February: 172-74. (Reprinted in F. Cioffi, Freud and the Question of Pseudoscience, Open Court, 1998: 199-204).

4. Schatzman M. Freud: Who seduced whom? New Scientist 1992; 21 March: 34-7.

5. Esterson A. Seductive Mirage: An Exploration of the Work of Sigmund Freud, Open Court, 1993: 11-31.

6. Israëls H, Schatzman 5. The seduction theory. History Psychiat1993; iv: 23-59. 7. Esterson A. Jeffrey Masson and Freud's seduction theory: A new fable based on old myths History of the Human Sciences 1998; 11(1): 1-21.

8. Esterson A. The mythologising of psychoanalytic history: Deception and self-deception in Freud's accounts of the seduction theory episode. History of Psychiatry 2001; 12(3): 329-52. 9. Freud S. The Complete Letters of Sigmund Freud to Wilhelm Fliess 1897-1904. Trans. and edited by JM Masson. Harvard University Press, 1985: 141, 144.

10. Freud S. Heredity and the aetiology of Phess, 1985: 141, 144.755 . Further remarks on the neuro-psychoses of defence (1896): 164,168-69. Standard Edition 3 (Trans. by J. Strachey), Hogarth Press, 1953-74: 142-55 and 162-85.

11. Freud S. Studies on Hysteria (189S): 110-11, 270*72. Standard Edition 2.

11. Freud S. Studies on Hysteria (189S): 110-11, 270-72. Standard Edition 2.
12. Freud, S. The aetiology of hysteria (1896): 192-93. Standard Edition 3: 189-221.

13. Ibid: 204 .

14. Ibid: 203 . 